\title{
Frequency Dispersion of Double Layer Capacitance of Polyaniline-Coated Electrodes Under the Conducting State
}

\author{
Zhaohao Wang ${ }^{1}$, Koichi Jeremiah Aoki ${ }^{2}$, Jingyuan Chen ${ }^{1}$, Xiangdong Zeng ${ }^{1}$ \\ ${ }^{1}$ Department of Applied Physics, University of Fukui, Fukui, Japan \\ ${ }^{2}$ Electrochemical Museum, Fukui, Japan \\ Correspondence: Jingyuan Chen, Department of Applied Physics, University of Fukui, 3-9-1 Bunkyo, Fukui, $910-0017$ \\ Japan. E-mail: jchen@u-fukui.ac.jp
}

Received: January 28, 2018 Accepted: April 3, 2018 Online Published: April 11, 2018

doi:10.5539/ijc.v10n2p25

URL: https://doi.org/10.5539/ijc.v10n2p25

\begin{abstract}
The double layer capacitance of polyaniline (PANi)-coated electrode in acidic solution exhibited little frequency dispersion under the emeraldine (electrically conducting) state, while it showed large frequency dispersion under the insulating state. The former has a possibility of working as such an ideal capacitor that it may generate neither heat in iterative charge-discharge processes nor leakage of stored charge. The frequency dispersion is generally expressed by $f^{\lambda}$ for ac-frequency $f$ and a constant $\lambda$. This power law is ascribed to orientation of solvent dipoles rather than non-uniform distribution of ions. The value of $\lambda$ under the conducting state was close to zero, implying the orientation to be facilitated by less interaction of solvents. The less interaction was supported indirectly with strain-stress curves of PANi by atomic force microscopy. $\lambda$-Values close to zero were retained even for thick PANi films.
\end{abstract}

Keywords: frequency dispersion of double layer capacitance, polyaniline-coated electrode, ac-impedance, power law by ac-frequency

\section{Introduction}

Polyaniline (PANi) exhibits electric conductivity in acidic solution under the oxidized state called emeraldine (MacDiarmid, et al., 1989; McManus, et al., 1987). The electric features of PANi-coated films have often been examined by use of ac-impedance techniques. Interpretation of the impedance data inevitably needs equivalent circuits composed of electronic elements such as ideal resistors and capacitors, which should be translated to electrode reaction mechanisms. Since equivalent circuits do not correspond uniquely to electrochemical reaction mechanisms (Brug, et al., 1984), suggested equivalent circuits do not always lead to an interpretation of the mechanisms. There are some complications (Deslouis, et al., 1999) that avoid unique interpretation especially for PANi films. They include (a) redox reactions which convert the states between the insulator and the conductor, (b) a function of electrically conducting porous PANi films as an electrode (Ren, et al., 1995), (c) hysteresis responding to such a long applied voltage change (Heinze, et al., 1987; Feldberg, et al., 1988) that it can be expressed quantitatively by logarithmic time-dependence (Aoki, et al., 1994; Odin, et al., 1992), (d) undistinguished Faradaic currents from capacitive ones (Heinze, et al., 1988; Feldberg, 1984), which has been extensively discussed (MacDiarmid, et al., 1989), and (e) complicated contribution of ions (Deslouis, et al., 1999; Benyaich, et al., 1996). Item (a) is coupled with (b) to expand or shrink the conducting zone over the film, called the propagation of the conducting zone (Aoki, et al., 1992; Aoki, et al., 1994). Since the expansion of the conducting zone increases the capacitive current through $(\mathrm{d})$, it is not easy to estimate reaction mechanisms from equivalent circuits.

Equivalent circuits of PANi films suggested so far are a parallel resistor-capacitor circuit in series with a resistor (Passiniemi, et al., 1995; Fernandes, et al., 2008, Aggas, 2015), nested resistance-capacitance blocks (Sarac, et al., 2008), dual rail transmission line models (Rubinstein, et al., 1987; Kalaji, et al., 1991; Mondal, et al., 2005), circuits including capacitance and inductance as parasitic stay impedance (Horvat-Radosevic, et al., 2009), circuits extracting significant contributions of coupled electron-ion transport inside a film (Vorotyntsev, et al., 1999), and power law of the impedance with respect to frequency (Babu, et al., 2013; Ravikiran, et al., 2006; Hui, et al., 2004; Ravikiran, et al., 2015). Unfortunately, they have not included systematically the frequency dispersion of the double layer (DL) capacitance such as the constant phase element (CPE) (Brug, et al., 1984; Lasia, et al., 1999; Nyikos, et al., 1985; Zoltowski, 1998) or the power law (Aoki, et al., 2013; Hou, et al., 2013; Zhao, et al., 2014; Hou, et al., 2014; Wang, et al., 2015). 
The basic concept of the frequency dispersion is not due to a combination of ideal capacitances and resistances, but lies in the charge $q$ stored in a time-dependent DL capacitance $C$ and the voltage $V$, as represented by the current, $I=\mathrm{d} q / \mathrm{d} t=$ $\mathrm{d}(\mathrm{CV}) / \mathrm{d} t$, according to the definition of $C$. Letting the angular velocity of the ac-voltage $V_{0}$ in amplitude be $\omega$, the time-derivative for the ac voltage $V=V_{0} \mathrm{e}^{i \omega t}$ becomes

$$
I=V_{0} \mathrm{e}^{i \omega t}(i \omega C+\mathrm{d} C / \mathrm{d} t)
$$

where $i$ is the imaginary unit. If the time $t$ in $\mathrm{d} C / \mathrm{d} t$ is replaced by $\omega$ through $t \rightarrow t^{\prime}=1 / \omega$, eq. 1 can be rewritten through $\mathrm{d} C / \mathrm{d} t^{\prime}=-\omega^{2} \mathrm{~d} C / \mathrm{d} \omega$ as

$$
I=V_{0} \mathrm{e}^{i \omega t}\left(i \omega C-\omega^{2} \mathrm{~d} C / \mathrm{d} \omega\right)
$$

Since the current in eq. 2 is composed of a series combination of the real term and the imaginary one, the equivalent circuit should be a parallel combination of the capacitance $C_{\mathrm{p}}$ and the resistance $R_{\mathrm{p}} \equiv-1 /\left(\omega^{2} \mathrm{~d} C_{\mathrm{p}} / \mathrm{d} \omega\right)$, where $C$ in eq.2 was represented as $C_{\mathrm{p}}$ for stressing the parallel. The parallel resistance, $R_{\mathrm{p}}$, is caused from a delay of the capacitance associated with the phase shift of $90^{\circ}$. Since the capacitance itself brings about the response with the $90^{\circ}$ shift, $R_{\mathrm{p}}$ turns out to be shifted by $180^{\circ}$, belonging to an in-phase component. Then the impedance at the electrode|solution (E) interface is given by

$$
Z_{\mathrm{E}}=\left(i \omega C_{\mathrm{pE}}-\omega^{2} \mathrm{~d} C_{\mathrm{pE}} / \mathrm{d} \omega\right)^{-1}
$$

where the subscript $\mathrm{E}$ means the electrode|solution interface. The imaginary component of $Z_{\mathrm{E}}$ often has shown a linear relation with the real component, i.e. a line in the Nyquist plot, of which slope $-C_{\mathrm{pE}} /\left(\omega \mathrm{d} C_{\mathrm{pE}} / \mathrm{d} \omega\right)$ is a constant. Letting the slope be $1 / \lambda_{\mathrm{E}}$ for a constant $\lambda_{\mathrm{E}}$ (close to 0 ), we obtain

$$
C_{\mathrm{pE}}=\left(C_{\mathrm{pE}}\right)_{1 \mathrm{~Hz}} f^{-\lambda_{\mathrm{E}}}
$$

as a result of solving the differential equation (Aoki, et al., 2018). Values of $\lambda_{\mathrm{E}}$ are independent of area of an electrode, i.e. independent of choosing a projected area or an area on molecular scale. The logarithmic law in eq. 4 has been verified for various solvents and electrodes (Aoki, et al., 2013; Hou, et al., 2013). Inserting eq.4 into eq. 3 yields

$$
Z_{\mathrm{E}}=\left[\omega C_{\mathrm{pE}}\left(i+\lambda_{\mathrm{E}}\right)\right]^{-1}
$$

Since PANi is electrically conducting material especially at the oxidized form, it works as an electrode. The interface between the electrode-like conducting film and the solution should also provide a double layer impedance, denoted by $Z_{\mathrm{F}}$ (film|solution) Therefore, there is the other impedance, $Z_{\mathrm{F}}$, at the film|solution interface, which is predicted to have a form similar to $Z_{\mathrm{E}}$, as illustrated in Fig. 1, i.e.

$$
Z_{\mathrm{F}}=\left[\omega C_{\mathrm{pF}}\left(i+\lambda_{\mathrm{F}}\right)\right]^{-1}
$$

A film resistance between the electrode and the film|solution interface, $R_{\mathrm{F}}$, is involved in the observed impedance. Furthermore, the solution resistance, $R_{\mathrm{S}}$, takes part in the total impedance, $Z$. Since the impedance, $Z-R_{\mathrm{s}}$, is given by the parallel combination of $Z_{\mathrm{E}}$ and $Z_{\mathrm{F}}+R_{\mathrm{F}}$, we have

$$
\frac{1}{Z-R_{\mathrm{s}}}=\frac{1}{Z_{\mathrm{E}}}+\frac{1}{Z_{\mathrm{F}}+R_{\mathrm{F}}}
$$

Our subject is to evaluate $C_{\mathrm{pF}}$, and $R_{\mathrm{F}}$ by variations of $Z$ with frequency in the PANi films. Dependence of these values on frequency and dc-potentials may provide electronic properties of PANi films. Especially, we pay attention to values of $\lambda_{\mathrm{F}}$ from $\mathrm{d} C_{\mathrm{pF}} / \mathrm{d} \omega$, which imply time-dependent parameters of the capacitor. The time-dependence is significant for energetic reversibility of supercapacitors in charge-discharge processes. We will find very small values of $\lambda_{F}$, which may demonstrate reversibility of the charge/discharge processes from a physicochemical viewpoint. This work does not include any kinetics for the redox reaction because we want to extract the DL properties accurately not to be disturbed by the faradaic reactions. 


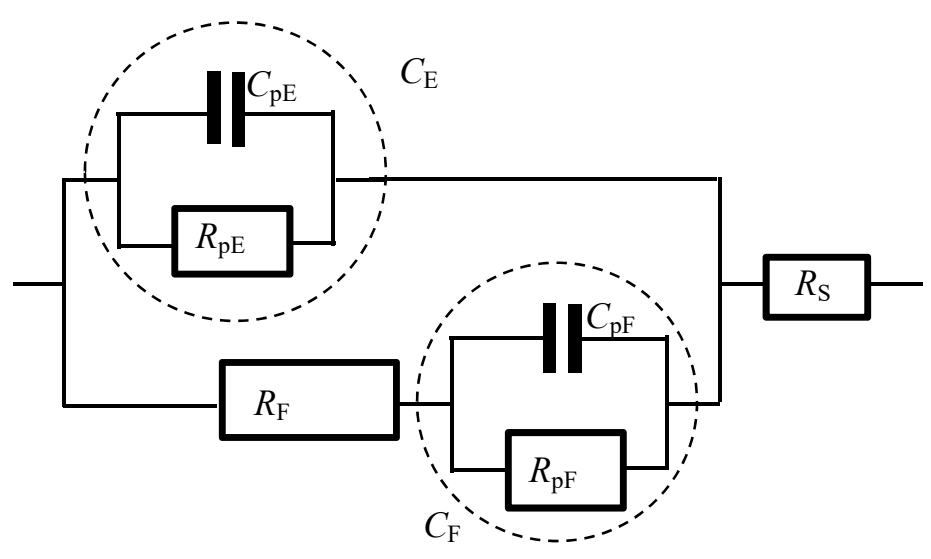

Figure 1. Equivalent circuits of PANi-coated electrode

\section{Experiment}

Water was distilled and then ion-exchanged with an ultrapure water system, CPW-100 (Advantec, Tokyo). All the chemicals were of analytical grade. The working electrode was a platinum wire $0.5 \mathrm{~mm}$ in diameter, which was inserted into solution by a given length ca. $8 \mathrm{~mm}$. The accurate length was measured by means of an optical microscope. The inserted wire electrode is useful for avoiding the stray capacitance, which is caused at disk-shielded electrodes by crevice of insulator|electrode boundaries. The reference electrode and the counter electrode were, respectively, $\mathrm{Ag} \mid \mathrm{AgCl}$ in saturated $\mathrm{KCl}$ and a platinum coil. Cyclic voltammetry and ac-impedance measurements were carried out with a potentiostat, Compactstat (Ivium Tech., Netherlands). Ac-impedance was obtained by applying ac-voltage of the $10 \mathrm{mV}$ amplitude superimposed on a given value of dc-potential $\left(E_{\mathrm{dc}}\right)$ ranging from -0.1 to $0.5 \mathrm{~V} \mathrm{vs}$. $\mathrm{Ag} \mid \mathrm{AgCl}$ in the frequency domain from $1 \mathrm{~Hz}$ to $10 \mathrm{kHz}$.

PANi films were synthesized with electrochemical oxidation of $0.1 \mathrm{M}\left(=\mathrm{mol} \mathrm{dm}{ }^{-3}\right)$ aniline in $1.0 \mathrm{M}$ sulfuric acid at the platinum wire. The oxidation was made by cyclic voltammetry of which potential ranged from -0.15 to $0.80 \mathrm{~V}$ vs. $\mathrm{Ag} \mid \mathrm{AgCl}$ at a given cycle number, ranging from 40 to 300 , at the scan rate $30 \mathrm{mV} \mathrm{s}^{-1}$. Atomic force microscope (AFM) was Nanocute (Hitachi). Film thickness was estimated from the assumptions of the one electron reaction of leucoemeraldine to emeraldine per four-aniline unite (MacDiarmid, A.G., \& Epstein, A.J., 1989) and the density $1.35 \mathrm{~g}$ $\mathrm{cm}^{-3}$ of PANi films. Then the charge density $0.01 \mathrm{C} \mathrm{cm}^{-2}$ for the redox reaction corresponds to $0.3 \mu \mathrm{m}$ thickness. The film thickness was $0.5 \mu \mathrm{m}$, unless otherwise stated.

\section{Results and Discussion}

Fig. 2 shows Nyquist plots of a PANi film at three dc-potentials, $E_{\mathrm{dc}}$. The plots at the sufficiently (a) reduced and (c) oxidized PANi films show slanted lines rather than a vertical line, like the CPE behavior (Brug, et al., 1984; Lasia, et al., 1999; Nyikos, et al., 1985; Zoltowski, et al., 1998). When $Z_{\mathrm{E}}>>Z_{\mathrm{F}}+R_{\mathrm{F}}$, eq.7 becomes $Z=Z_{\mathrm{F}}+\left(R_{\mathrm{s}}+R_{\mathrm{F}}\right)$, which is composed of a series combination of the impedance at the film|solution interface and the resistances of the PANi film and the solution. The real and the imaginary parts are represented respectively by

$$
\begin{aligned}
& Z_{1}=\lambda_{\mathrm{F}} /\left[\omega C_{\mathrm{F}}\left(\lambda_{\mathrm{F}}^{2}+1\right)\right]+R_{\mathrm{s}}+R_{\mathrm{F}} \\
& -Z_{2}=1 /\left[\omega C_{\mathrm{F}}\left(\lambda_{\mathrm{F}}^{2}+1\right)\right]
\end{aligned}
$$

or

$$
Z_{1}=-\lambda_{\mathrm{F}} Z_{2}+R_{\mathrm{s}}+R_{\mathrm{F}}
$$

Then the Nyquist plot shows a line with a slope of $1 / \lambda_{\mathrm{F}}$ and an intercept of $R_{\mathrm{s}}+R_{\mathrm{F}}$ on the $Z_{1}$ axis. On the other hands, eq. 7 for $Z_{\mathrm{E}}<<Z_{\mathrm{F}}+R_{\mathrm{F}}$ becomes $Z=R_{\mathrm{S}}+Z_{\mathrm{E}}$, of which Nyquist plot is given by

$$
Z_{1}=-\lambda_{\mathrm{E}} Z_{2}+R_{\mathrm{s}}
$$

Since the plots in Fig. 2 for the reduced (a) and the oxidized (c) forms take lines, either of eq. 9 or eq.10 is possible, i.e. (either $\lambda_{\mathrm{F}}$ or $\lambda_{\mathrm{E}}$ ) $=0.5$ (a) and 0.02 (c). The impedance values at the oxidized PANi (at $82 \mathrm{~Hz}$ to be marked as a cross) are much smaller than those at the reduced one. Since the values of the impedance vary largely with the redox state of 
PANi films, the difference in the slopes of the Nyquist plots should be ascribed to $\lambda_{\mathrm{F}}$ rather than $\lambda_{\mathrm{E}}$. As a result, we can infer $Z_{\mathrm{E}} \gg Z_{\mathrm{F}}+R_{\mathrm{F}}$.

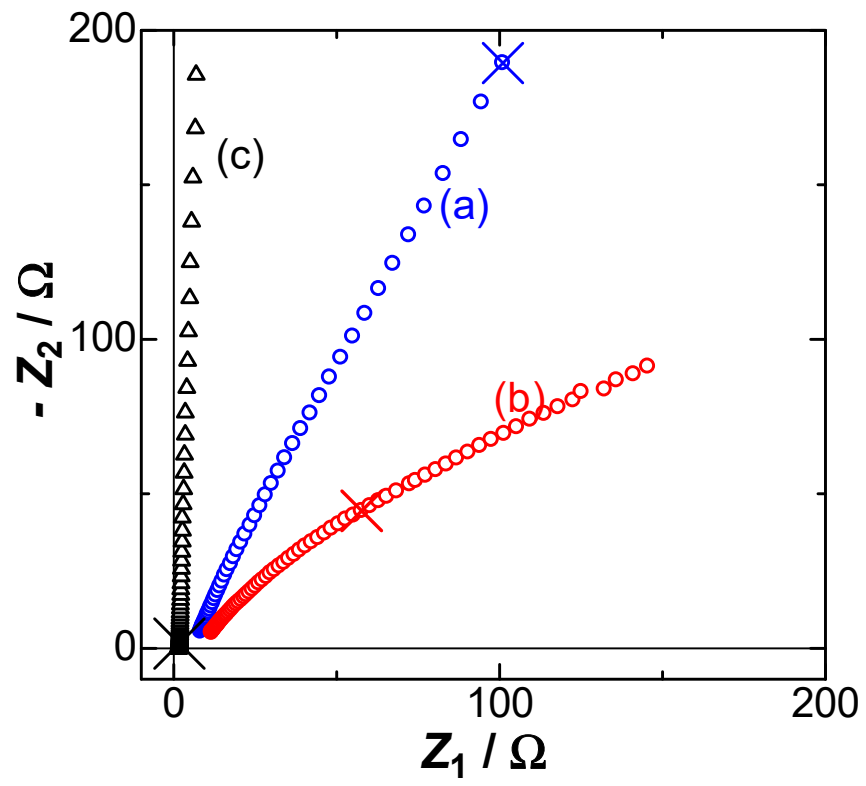

Figure 2. Nyquist plots at the PANi-coated Pt electrode in $1 \mathrm{M} \mathrm{H}_{2} \mathrm{SO}_{4}$ solution at $E_{\mathrm{dc}}=$ (a) 0.0 , (b) 0.15 and (c) $0.40 \mathrm{~V}$ vs. $\mathrm{Ag} \mid \mathrm{AgCl}$. The cross marks are at $f=82 \mathrm{~Hz}$

Fig. 3 shows variation of the intercept of the Nyquist plots on the $Z_{1}$ axis with the dc-potentials, together with the voltammogram of the PANi film in the upper part. The intercept represents $R_{\mathrm{S}}+R_{\mathrm{F}}$, according to eq.9. Values of the resistance $\left(R_{\mathrm{S}}+R_{\mathrm{F}}\right)$ for $E_{\mathrm{dc}}<0.1 \mathrm{~V}$ are six times larger than those for $E_{\mathrm{dc}}>0.2 \mathrm{~V}$ in Fig. 3. In contrast, the resistivity of the reduced PANi film has been reported to be larger by a few order in magnitude than that of the oxidized form (McManus, et al., 1987; Paul, et al., 1985; Ofer, et al., 1990; Csahók, et al., 2000). Our result in Fig. 3 is consistent with the large ratio of the resistivity, because the difference between the maximum resistance $E_{\mathrm{dc}}<0.1 \mathrm{~V}$ and the minimum one $E_{\mathrm{dc}}>0.2 \mathrm{~V}$ can be attributed to the film resistance $\left(R_{\mathrm{F}}\right)$ through the redox reaction, the net ratio being a few order in magnitude.

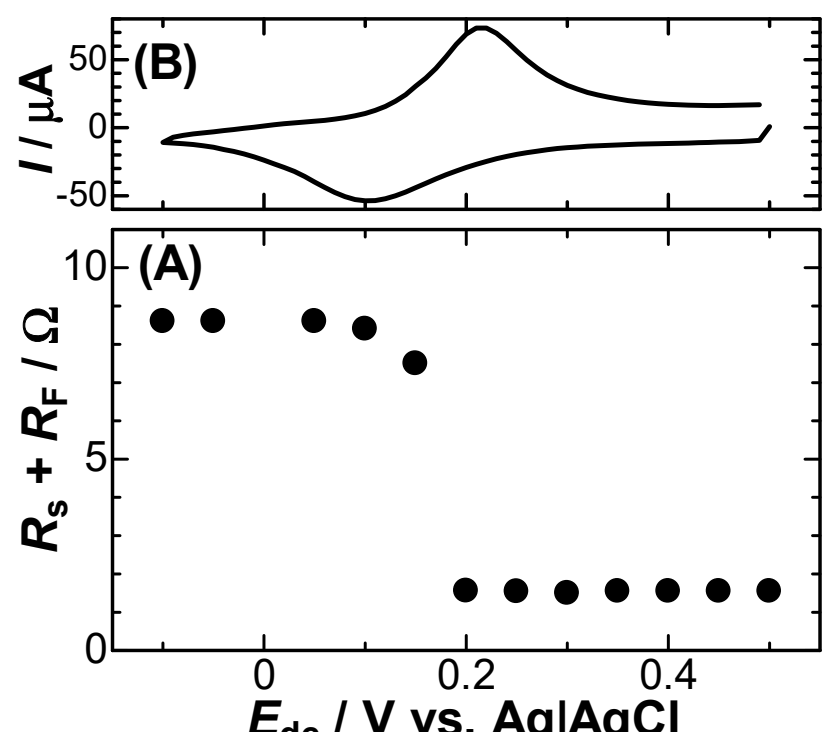

Figure 3. (A) Variation of the resistance with the dc-potential, and (B) voltammogram of the PANi film in $1 \mathrm{M} \mathrm{H}_{2} \mathrm{SO}_{4}$ solution at the scan rate of $10 \mathrm{mV} \mathrm{s}^{-1}$

We let the admittance of $Z_{\mathrm{F}}$ be $Y_{\mathrm{F}}$, i.e.,

$$
Y_{\mathrm{F}}=\frac{1}{Z-\left(R_{\mathrm{s}}+R_{\mathrm{F}}\right)}=\frac{Z_{1}-\left(R_{\mathrm{S}}+R_{\mathrm{F}}\right)-i Z_{2}}{\left(Z_{1}-\left(R_{\mathrm{s}}+R_{\mathrm{F}}\right)\right)^{2}+Z_{2}^{2}}
$$


According to eq.6, the admittance can be rewritten through the $f$-dependent capacitance:

$$
Y_{\mathrm{F}}=\left(i+\lambda_{\mathrm{F}}\right)\left(\omega C_{\mathrm{pF}}\right)=2 \pi\left(i+\lambda_{\mathrm{F}}\right) C_{\mathrm{pF}, 1 \mathrm{~Hz}} f^{\lambda_{\mathrm{F}}+1}
$$

Values of the imaginary part, $Y_{\mathrm{F} 2}$, calculated from eq.11 were plotted against the frequency in the logarithmic scale in Fig. 4. The linearity supports the validity of eq.12, of which slopes and intercepts give $\lambda_{\mathrm{F}}$ and $C_{\mathrm{pF}, \mathrm{Hz}}$, respectively.

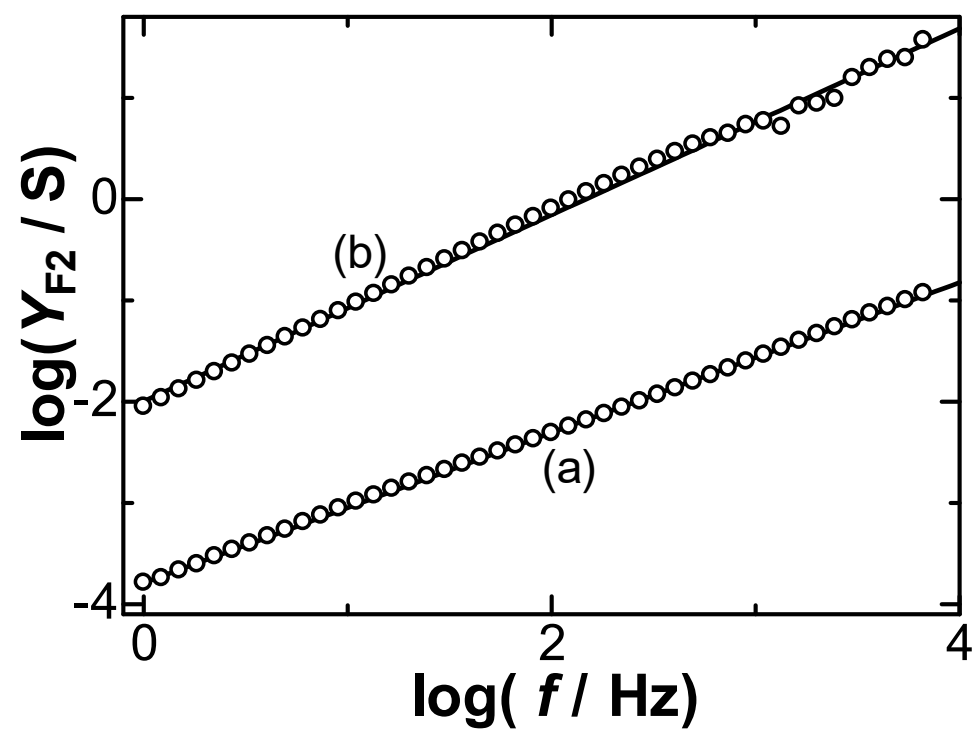

Figure 4. Logarithmic plots of $Y_{\mathrm{F} 2}$ against frequency at $E_{\mathrm{dc}}=$ (a) 0.0 and (b) $0.4 \mathrm{~V}$ vs. $\mathrm{Ag} \mid \mathrm{AgCl}$

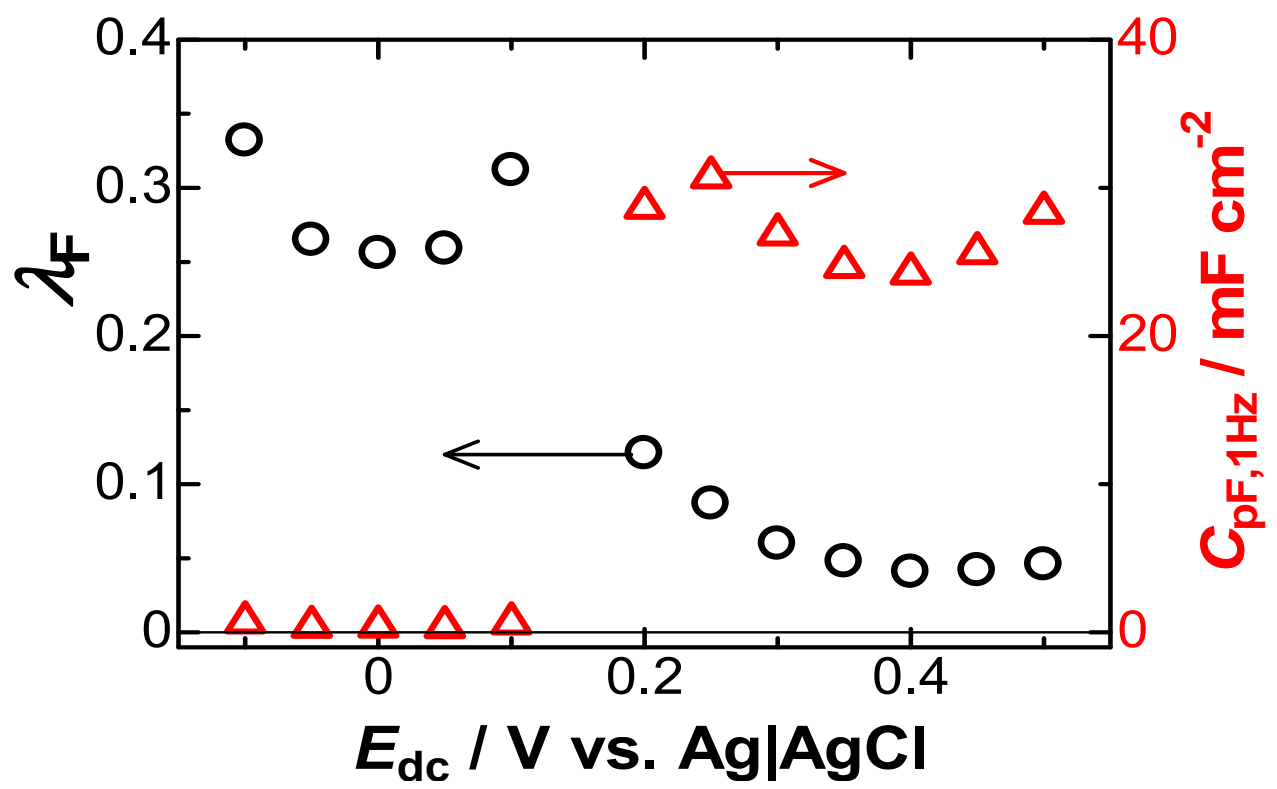

Figure 5. Dependence of (circles) $\lambda_{\mathrm{F}}$ and (triangles) $C_{\mathrm{pF}, 1 \mathrm{~Hz}}$ on the dc-potential

Fig. 5 shows the variation of $C_{\mathrm{pF}, 1 \mathrm{~Hz}}$ with the dc-potentials on the right axis. The oxidized PANi which lies in the potential domain $E_{\mathrm{dc}}>0.15 \mathrm{~V}$ exhibits values of $C_{\mathrm{pF}, 1 \mathrm{~Hz}}$ much larger than of the reduced one (in $E_{\mathrm{dc}}<0.15 \mathrm{~V}$ ). The large capacitance values can readily be understood in terms of the porous, conducting PANi film, which provides huge net area of the electric conducting material, as if the electrode area were large. They are 1000 times as large as those at Pt|aqueous solution interfaces. In contrast, the reduced PANi exhibits $400-700 \mu \mathrm{F} \mathrm{cm}{ }^{-2}$, which is more than 10 times 
larger than at Pt|aqueous solution interfaces. The 10 time larger capacitance supports the assumption of $Z_{\mathrm{E}}>Z_{\mathrm{F}}+R_{\mathrm{F}}$ for eq. 8 and eq.9, or supports that the capacitance at the film|solution interface is much predominant over that at the electrode|solution interface. As a result, the capacitance in Fig. 5 should be $C_{\mathrm{pF}}$ rather than $C_{\mathrm{pE}}$. Although values of the net area of the interface are ambiguous, values of $\lambda_{\mathrm{E}}$ and $\lambda_{\mathrm{F}}$ have been determined independently of the area from the plot in Fig. (4).

Fig. 5 also shows the variation of $\lambda_{\mathrm{F}}$ with the dc-potentials on the left axis. The oxidized PANi provides values of $\lambda_{\mathrm{F}}(=$ $0.04)$ as small as values at the highly oriented pyrolytic graphite $(\lambda=0.06)$ and thin $(<0.1 \mu \mathrm{m})$ films of graphene flakes in aqueous solutions (Wang, et al.,2015) in comparison with at platinum electrodes $(\lambda \approx 0.1)$ (Aoki, et al., 2013; Hou, et al., 2013; Zhao, et al., 2014; Hou, et al., 2014). Smaller values of $\lambda$ imply less contribution of frequency dispersion or of the associated resistance expressed by $\omega^{-2}(\mathrm{~d} C / \mathrm{d} \omega)^{-1}$ in eq.2. They are ascribed to high feasibility of the orientation of solvent dipoles (Aoki, 2016). The thicker are electrically conducting materials, the longer is the orientation time of dipoles generally (Wang, et al., 2015). PANi films are often as thick as of $\mu \mathrm{m}$ order, and hence are predicted to yield large values of $\lambda_{\mathrm{F}}$. The evaluated small values of $\lambda_{\mathrm{F}}$ can be attributed to the high feasibility of the orientation of water molecules around the oxidized form of PANi molecular wires.

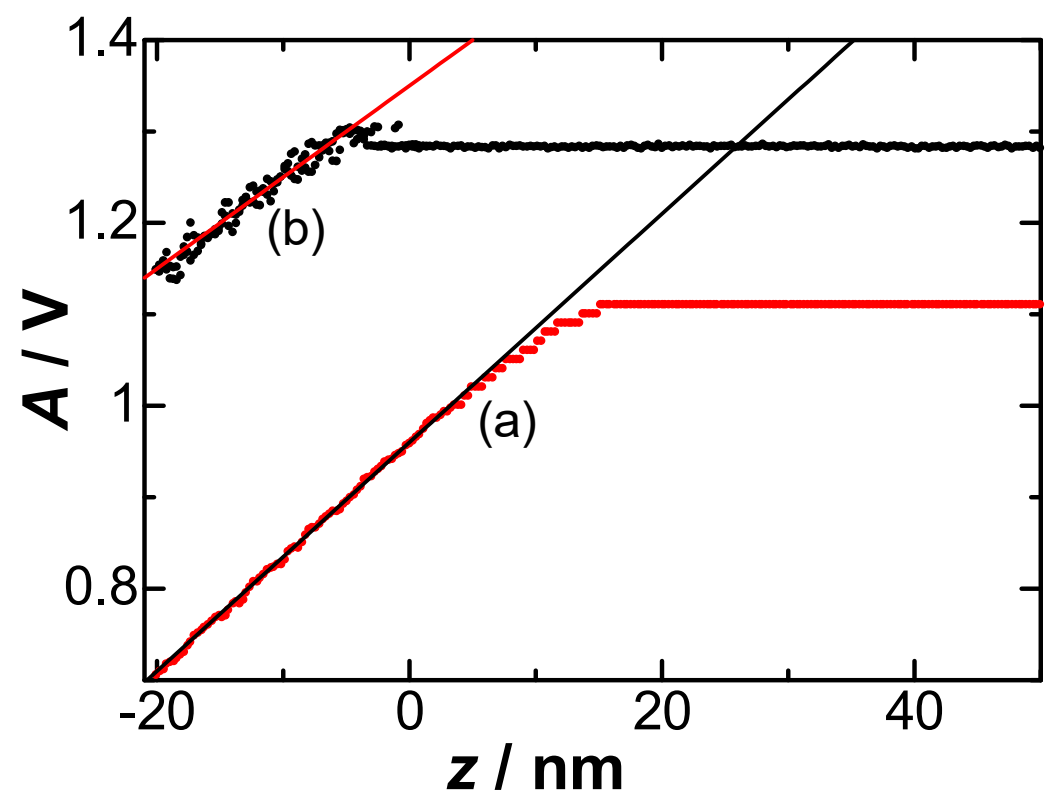

Figure 6. Force-depth curves when a cantilever of AFM was pressed on the PANi film under (a) the reduced state and (b) the oxidized one

The feasibility may be related with microscopic Young's modulus of PANi. The mechanical properties such as macroscopic moduli of PANi films have been discussed in the context of the redox states (Mohamoud, et al., 2007; Valentová, et al., 2010; Han, et al., 2004; Yu, et al., 2009). The Young moduli of the oxidized state are smaller than those of the reduced one (Valentová, et al., 2010). We regarded the modulus as a slope of stress-strain curves or force-depth curves by the force mode of atomic force microscope (Passeri, et al., 2011). Fig. 6 shows the force-depth curves of the reduced and the oxidized forms of PANi films. The curves varied with locations of touching a cantilever with the film, but they were always composed of two lines with a critical point. Two lines with a junction have been exhibited in most PANi films (Mohamoud, et al., 2007; Valentová, et al., 2010; Han, et al., 2004; Yu, et al., 2009; Passeri, et al., 2011) although complicated curves appeared in a single polymer chain (Yu, et al., 2009). The slope of force against the depth, proportional to the Young modulus, of the oxidized form $\left(8.8 \pm 3.8 \mathrm{mV} \mathrm{nm}^{-1}\right)$ is smaller than that of the reduced one $\left(10.5 \pm 5.9 \mathrm{mV} \mathrm{nm}^{-1}\right)$, where these values were averaged for 46 curves at different locations, and the errors mean the standard deviation. Therefore, the oxidized form is higher feasibility of the orientation for generating the capacitance than the reduced form. This fact supports the dependence of $\lambda_{\mathrm{F}}$ on the dc-potential.

Supercapacitors are desired to have such physical properties as a) high density of capacitance, b) high voltage, c) reversibility without heat generation, and d) the absence of leakage of current through the DL layer. Item d) is more essential from the physicochemical viewpoints than the others which have resorted practically to hybridization of polyaniline with carbons (Cheng, et al., 2013; Tayel, et al., 2016) as pseudocapacitors (Liu, et al., 2014; Gup, et al., 
2015; Leary, et al., 2016; Liu, D., et al., 2015; Sarangapani, et al., 1996) and morphological variations I, II, III(Grover, et al., 2016; Chen, et al., 2013; Singu, et al., 2012). It includes two causes: one is the leakage due to time-variation of voltage through $R_{\mathrm{pF}}\left(=-1 /\left(\omega^{2} \mathrm{~d} C_{\mathrm{pF}} / \mathrm{d} \omega\right)\right)$ and the other is due to redox reactions. The former is related with $\lambda_{\mathrm{F}}$. Since an increase in the film thickness generally increases $\lambda_{\mathrm{F}}$, item a) is competitive with $\lambda_{\mathrm{F}}$ in d). In order to know a degree of the competition, we examine the relation between values of $\lambda_{\mathrm{F}}$ and the film thickness or the redox charge involved in PANi films. We determined the amount of the redox charge from the linear sweep voltammograms on the assumption that the observed current, $I(E)$, was the sum of the current, $I_{\mathrm{rd}}(E)$, for the surface wave of the redox reaction and the capacitive current of the oxidized PANi. The capacitive component can be expressed in terms of the integral of $k I_{\mathrm{rd}}(E)$, as illustrated in the inset of Fig. 7, where $k$ is a proportional constant. The solution of the integral equation yields (Tezuka, et al., 1989)

$$
I(E)=I_{\mathrm{rd}}(E)+k \int_{E_{i n}}^{E} I_{\mathrm{rd}}(u) \mathrm{d} u
$$

or

$$
I_{\mathrm{rd}}(E)=I(E)-k \int_{E_{\text {in }}}^{E} I(u) \mathrm{e}^{-k(E-u)} \mathrm{d} u
$$

where $E_{\text {in }}$ is the initial potential. A value of $k$ was determined so that $I_{\mathrm{rd}}(E)=0$ for sufficiently positive potential, e.g. 0.4 $\mathrm{V}$ vs. $\mathrm{Ag} \mid \mathrm{AgCl}$. We regard the integral of $I_{\mathrm{rd}}$ as the redox charge $Q$. We examined the reliability of $k$ within $6 \%$ errors for different film thicknesses and scan rates, as consistent with the previous result (Tezuka, et al., 1989). Fig. 7 shows the variation of $\lambda_{\mathrm{F}}$ for the oxidized state (at $E_{\mathrm{dc}}=0.4 \mathrm{~V}$ ) with the redox charge density, $\sigma=Q / S$ for the projected surface area $S$. Values of $\lambda_{\mathrm{F}}$ did not vary with the film thickness within the standard deviation. In contrast, $C_{\mathrm{pF}, 1 \mathrm{~Hz}}$ increased proportionally with the film thickness (on the right axis), as conventionally predicted without complications. Therefore, item a) is not competed with $\lambda_{\mathrm{F}}$. Even a thick PANi film can keep values of $\lambda_{\mathrm{F}}$ to be close to zero, i.e. an ideal capacitor.

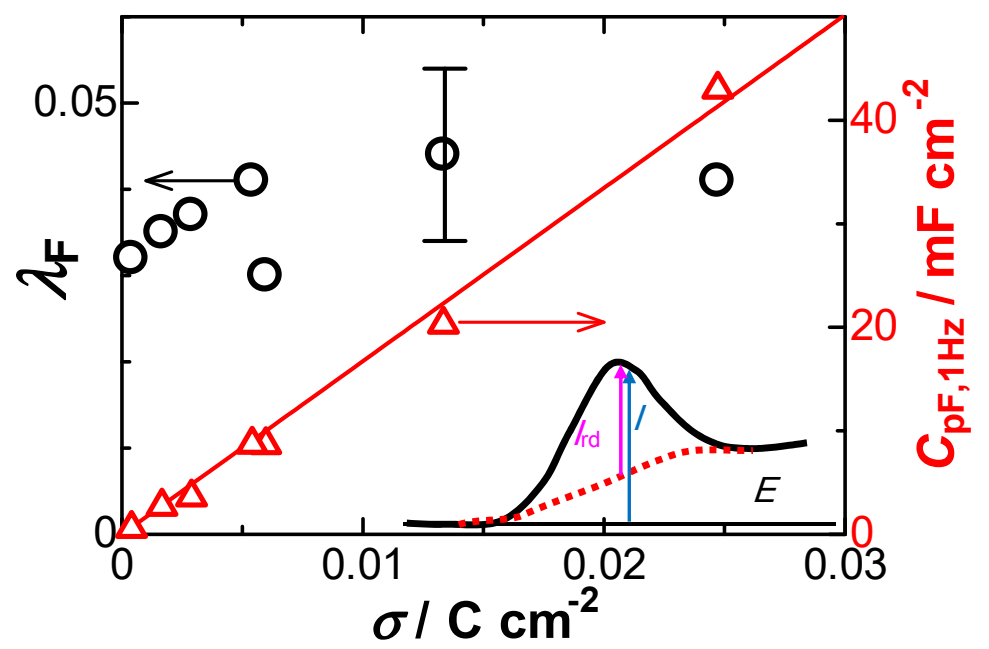

Figure 7. Variations of $\lambda_{\mathrm{F}}$ (circles) and $C_{\mathrm{pF}, 1 \mathrm{~Hz}}$ (triangles) with the charge density of the PANi film

The bar means the standard deviation of $\lambda_{\mathrm{F}}$. The inset illustrates a linear sweep voltammogram (solid curve) and a charging current (dotted curve)

IS. Grover, S. Goel, R. B. Marichi, V. Sahu, G. Singh, R. K. Sharma, Polyaniline All Solid-State Pseudocapacitor: Role of Morphological Variations in Performance Evolution. Electrochim. Acta, 196(2016) 131-139. https://doi.org/10.1016/j.electacta.2016.02.157

IIW. Chen, R.B. Rakhi, H. N. Alshareef, Facile synthesis of polyaniline nanotubes using reactive oxide templates for high energy density pseudocapacitors, Mater. Chem. A, 1(2013) 3315-3324. https://doi.org/10.1039/C3TA00499F

IIIB. S. Singu, P. Srinivasan, S. Pabba, Benzoyl peroxide oxidation route to nano form polyaniline salt containing dual dopants for pseudocapacitor. J. Electrochem Soc., 159(2012) A6-A13. http://jes.ecsdl.org/content/159/1/A6.short 


\section{Conclusion}

Ac-impedance of PANi films obeys the equivalent circuit in Fig. 1, in which most of the ac-current flows through the film|solution rather than electrode|solution, represented by $Z_{\mathrm{E}} \gg Z_{\mathrm{F}}+R_{\mathrm{F}}$. The capacitance of the PANi film is followed by the power law of the frequency, similar to the power law at the electrode|solution interface. The values are quite different, i.e., $C_{\mathrm{pF}}>>C_{\mathrm{pE}}$ and $\lambda_{\mathrm{F}}<0.04<\lambda_{\mathrm{E}}$. Since the conducting state of the PANi can be regarded as an assembly of conducting wires, the former inequality is obvious for the electrode area. The latter is significant for applying PANi films to supercapacitors in the viewpoint of suppressing heat generation at the film|solution interface in charge-discharge processes.

\section{References}

Aggas, J. (2015). Electrical Characterization of Gold and Platinum Thin Film Electrodes with Polyaniline Modified Surfaces. All thesis. Paper 2259. http://tigerprints.clemson.edu/cgi/viewcontent.cgi?article=3264\&context=all_theses

Aoki, K. J. (2016). Molecular interaction model for frequency-dependence of double layer capacitors. Electrochimica Acta, 188, 545-550. http://dx.doi.org/10.1016/j.electacta.2015.12.049

Aoki, K. J., Chen, J., \& Tang, P. (2018). Double layer impedance in mixtures of acetonitrile and water. Electroanalysis, in print. https://dx.doi.org/10.1002/elan.20180025

Aoki, K., \& Kawase, M. (1994). Introduction of a percolation threshold potential at polyaniline-coated electrodes. Journal of Electroanalytical Chemistry, 377(1-2), 125-129. https://doi.org/10.1016/0022-0728(94)03446-X

Aoki, K., Aramoto, T., \& Hoshino, Y. (1992). Photographic measurements of propagation speeds of the conducting zone in polyaniline films during electrochemical switching. Journal of Electroanalytical Chemistry, 340(1-2), 127-135. https://doi.org/10.1016/0022-0728(92)80293-D

Aoki, K., Cao, J., \& Hoshino, Y. (1994). Logarithmic relaxation of electrochemical insulating-to-conducting conversion at polyaniline films: interpretation by electric percolation. Electrochimica Acta, 39(15), 2291-2297. http://dx.doi.org/10.1016/0013-4686(94)E0181-X

Aoki, K., Hou, Y., Chen, J., \& Nishiumi, T. (2013). Resistance associated with measurements of capacitance in electric double layers. Journal of Electroanalytical Chemistry, 689, 124-129. https://doi.org/10.1016/j.jelechem.2012.10.004

Babu, V. J., Vempati, S., \& Ramakrishna, S. (2013). Conducting Polyaniline-Electrical Charge Transportation, Materials Sciences and Applications, 4(1), 1-10. https://doi.org/10.4236/msa.2013.41001

Benyaich, A., Deslouis, C., Moustafid, T. E., Musiani, M. M., \& Tribollet, B. (1996). Electrochemical properties of PANI films for different counter-ions in acidic $\mathrm{pH}$ analysed by impedance techniques. Electrochimica Acta, 41(11-12), 1781-1785. https://doi.org/10.1016/0013-4686(95)00495-5

Brug, G. J., Eeden, A. L. G., Van Den. Sluyters-Rehbach, M., \& Sluyters, J. H. (1984). The analysis of electrode impedances complicated by the presence of a constant phase element. Journal of Electroanalytical Chemistry, 176(1-2), 275-295. https://doi.org/10.1016/S0022-0728(84)80324-1

Chen, W., Rakhi, R. B., \& Alshareef, H. N. (2013). Facile synthesis of polyaniline nanotubes using reactive oxide templates for high energy density pseudocapacitors, Journal of Materials Chemistry A, 1(10), 3315-3324. https://doi.org/10.1039/C3TA00499F

Cheng, Q., Tang, J., Shinya, N., \& Qin, L. C. (2013). Polyaniline modified graphene and carbon nanotube composite electrode for asymmetric supercapacitors of high energy density. Journal of Power Sources, 241, 423-428. https://doi.org/10.1016/j.jpowsour.2013.04.105

Csahók, E., Vieil, E., \& Inzelt, G. (2000). In situ dc conductivity study of the redox transformations and relaxation of polyaniline films. Journal of Electroanalytical Chemistry, 482(2), 168-177. https://doi.org/10.1016/S0022-0728(00)00044-9

Deslouis, C., Moustafid, T. E., Musiani, M. M., Orazem, M. E., Provost, V., \& Tribollet, B. (1999). Effect of cations on the diffusivity of the charge carriers in polyaniline membranes. Electrochimica Acta, 44, 2087-2093. https://doi.org/10.1016/S0013-4686(98)00316-8

Feldberg, S. W. (1984). Reinterpretation of polypyrrole electrochemistry. Consideration of capacitive currents in redox switching of conducting polymers. Journal of the American Chemical Society, 106(17), 4671-4674. http://pubs.acs.org/doi/10.1021/ja00329a004 
Feldberg, S. W., \& Rubinstein, I. (1988). Unusual quasi-reversibility (UQR) or apparent non-kinetic hysteresis in cyclic voltammetry: An elaboration upon the implications of $\mathrm{N}$-shaped free energy relationships as explanation. Journal of Electroanalytical Chemistry, 240(1-2), 1-15. https://doi.org/10.1016/0022-0728(88)80308-5

Fernandes, E. G. R., Soares, D. A. W., \& Queiroz, A. A. A. D. (2008). Electrical properties of electrodeposited polyaniline nanotubes, Journal of Materials Science: Materials in Electronics 19(5), 457-462. https://link.springer.com/article/10.1007/s10854-007-9362-x

Grover, S., Goel, S., Marichi, R. B., Sahu, V., Singh, G., \& Sharma, R. K. (2016). Polyaniline All Solid-State Pseudocapacitor: Role of Morphological Variations in Performance Evolution. Electrochimica Acta, 196, 131-139. https://doi.org/10.1016/j.electacta.2016.02.157

Guo, F., Mia, H., Zhou, J., Zhao, Z., \& Qiu, J. (2015). Hybrid pseudocapacitor materials from polyaniline@multi-walled carbon nanotube with ultrafine nanofiber-assembled network shell. Carbon, 95, 323-329. https://doi.org/10.1016/j.carbon.2015.08.052

Han, D. H., \& Park, S. M. (2004). Electrochemistry of conductive polymers. 32. Nanoscopic examination of conductivities of polyaniline films. The Journal of Physical Chemicastry, B, 108(37), 13921-13927. http://pubs.acs.org/doi/abs/10.1021/jp0494279

Heinze, J., Bilger, R., \& Meerholz, K. (1988). Electrochemically Induced Structural Changes in Conducting Polymers. Berichte der Bunsengesellschaft für physikalische Chemie, 92(11), 1266-1271. https://doi.org/10.1002/bbpc.198800309

Heinze, J., Storzbach, M., \& Mortensen, J. (1987). Experimental and theoretical studies on the redox properties of conducting polymers. Berichte der Bunsengesellschaft für physikalische Chemie, 91(9), 960-967. https://doi.org/10.1002/bbpc.19870910926

Horvat-Radosevic, V., \& Kvastek, K. (2009). Three-electrode cell set-up electrical equivalent circuit applied to impedance analysis of thin polyaniline film modified electrodes. Journal of Electroanalytical Chemistry, 631(1-2), 10-21. https://doi.org/10.1016/j.jelechem.2009.03.003

Hou, Y., Aoki, K. J. Chen, J., \& Nishiumi, T. (2014). Solvent Variables Controlling Electric Double Layer Capacitance at the Metal-Solution Interface. The Journal of Physical Chemistry C, 118, 10153-10158. http://pubs.acs.org/doi/pdfplus/10.1021/jp5018289

Hou, Y., Aoki, K. J., Chen, J., \& Nishiumi, T. (2013). Invariance of Double Layer Capacitance to Polarized Potential in Halide Solutions. Universal Journal of Chemistry, 1(4), 162-169.

http://www.hrpub.org/journals/article_info.php?aid=741

Hui, D., Alexandrescu, R., Chipara, M., Morjan, I., Aldica, G., Chipara, M. D., \& Lau, K. T. (2004). Impedance spectroscopy studies on doped polyanilines, Journal of Optoelectronics and Advanced Materials, 6(3), 817-824. https://joam.inoe.ro/arhiva/pdf6_3/Hui.pdf

Kalaji, M., \& Pete, L. M. (1991). Optical and electrical AC response of polyaniline films, Journal of the Chemical Society, Faraday Transactions, 87(6), 853-860. http://pubs.rsc.org/en/content/articlelanding/1991/ft/ft9918700853

Lasia, A. (1999). In: B.E. Conway, J. Bockris, R.E. White, (Eds.), Electrochemical Impedance Spectroscopy and its Applications. Modern Aspects of Electrochemistry, Kluwer Academic/Plenum Publishers, New York, 32, 143-248. http://www.chem.uw.edu.pl/wp-content/uploads/2017/03/p1.pdf

Leary, J. D., Hamouda, F., Mazé, B., \& Pourdeyhimi, B. (2016). Preparation of pseudocapacitor electrodes via electrodeposition of polyaniline on nonwoven carbon fiber fabrics. Applied. Polymer Science, 133(16), 43315. http://onlinelibrary.wiley.com/doi/10.1002/app.43315/abstract

Liu, D., Wang, X., Deng, J., Zhou, C., Guo, J., \& Liu, P. (2015), Crosslinked carbon nanotubes/polyaniline composites as a pseudocapacitive material with high cycling stability. Nanomaterials, 5(2), 1034-1047. http://www.mdpi.com/2079-4991/5/2/1034/pdf

Liu, T., Finn, L., Yu, M., Wang, H., Zhai, T., Lu, X., Tong, Y., \& Li, Y. (2014). Polyaniline and polypyrrole pseudocapacitor electrodes with excellent cycling stability. Nano Letters, 14, 2522-2527. http://pubs.acs.org/doi/pdfplus/10.1021/nl500255v

MacDiarmid, A. G., \& Epstein, A. J. (1989). Polyanilines: a novel class of conducting polymers, Faraday Discussions of the Chemical Society, 88, 317-332. http://dx.doi.org/10.1039/DC9898800317

McManus, P. M., Cushman, R. J., \& Yang, S. C. (1987). Influence of Oxldation and Protonation on the Electrical Conductivity of Polyanillne. The Journal of Physical Chemistry, 91(3), 744-747. 
http://pubs.acs.org/doi/pdf/10.1021/j100287

Mohamoud, M. A., \& Hillman, A. R. (2007). The effect of anion identity on the viscoelastic properties of polyaniline films during electrochemical film deposition and redox cycling. Electrochimica Acta, 53(3), 1206-1216. https://doi.org/10.1016/j.electacta.2007.01.042

Mondal, S. K., Prasad, K. R., \& Munichandraiah, N. (2005). Analysis of electrochemical impedance of polyaniline films prepared by galvanostatic, potentiostatic and potentiodynamic methods. Synthetic Metals, 148(3), 275-286. https://doi.org/10.1016/j.synthmet.2004.10.010

Nyikos, L., \& Pajkossy, T. (1985). Fractal dimension and fractional power frequency-dependent impedance of blocking electrodes. Electrochimica Acta, 30(11), 1533-1540. http://dx.doi.org/10.1016/0013-4686(85)80016-5

Odin, C., Nechtshein, M., \& Hapiot, P. (1992). Kinetics of the charge-discharge process in conducting polymers: slow relaxation and hysteresis effects. Investigations on polyaniline by millimetric and ultramicroelectrodes. Synthetic Matals, 47(3), 329-350. https://doi.org/10.1016/0379-6779(92)90373-Q

Ofer, D., Crooks, R. M., \& Wrighton, M. S. (1990). Potential dependence of the conductivity of highly oxidized polythiophenes, polypyrroles, and polyaniline: finite windows of high conductivity. Journal of American Chemical Society, 112(22), 7869-7879. http://pubs.acs.org/doi/abs/10.1021\%2Fja00178a004

Passeri, D., Alippi, A., Bettucci, A., Rossi, M., Tamburri, E., \& Terranova, M. L. (2011). Indentation modulus and hardness of polyaniline thin films by atomic force microscopy. Synthetic Metals, 161(1-2), 7-12. https://doi.org/10.1016/j.synthmet.2010.10.027

Passiniemi, P., \& Väkiparta, K. (1995). Characterizaton of polyaniline blends with AC impedance measurements. Synthetic Metals, 69(1-3), 237-238. https://doi.org/10.1016/0379-6779(94)02432-X

Paul, E. W., Ricco, A., \& Wrighton, M. S. (1985). Resistance of polyaniline films as a function of electrochemical potential and the fabrication of polyaniline-based microelectronic devices. The Journal of Physical Chemistry, 89(8), 1441-1447. http://dx.doi.org/10.1021/j100254a028

Ravikiran, Y. T., Kotresh, S., Vijayakumari, S. C., Sajjan, K. C., Khened, B. S., \& Thomas, S. (2015). AC conductivity studies of p-toluenesulfonic acid doped polyaniline-sodium alginate composites, Cellulose Chemistry and Technology, 49(1), 21-28. http://www.cellulosechemtechnol.ro/pdf/CCT1(2015)/p.21-28.pdf

Ravikiran, Y. T., Lagare, M. T., Sairam, M., Mallikarjuna, N. N., Sreedhar, B., Manohar, S., ... Aminabhavi, T. M. (2006). Synthesis, characterization and low frequency AC conduction of polyaniline/niobium pentoxide composites. Synthetic Metals, 156(16-17), 1139-1147. https://doi.org/10.1016/j.synthmet.2006.08.005

Ren, X., \& Pickup, P. G. (1995). Impedance measurements of ionic conductivity as a probe of structure in electrochemically deposited polypyrrole films. Journal of Electroanalytical Chemistry, 396(1-2), 359-364. https://doi.org/10.1016/0022-0728(95)04064-U

Rubinstein, I., Sabatani, E., \& Rishpon, J. (1987). Electrochemical impedance analysis of polyaniline films on electrodes, Journal of the Electrochemical Society, 134(12), 3078-3083.

http://jes.ecsdl.org/content/134/12/3078.abstract

Sarac, A. S., Ates, M., \& Kilic, B. (2008). Electrochemical impedance spectroscopic study of polyaniline on platinum, glassy carbon and carbon fiber microelectrodes. International Journal of Electrochemical Science, 3, 777-786. http://electrochemsci.org/papers/vol3/3070777.pdf

Sarangapani, S., Tilak, B. V., \& Chen, C. P. (1996). Materials for electrochemical capacitors theoretical and experimental constraints. Journal of Electrochemical Society, 143(11), 3791-3799. http://jes.ecsdl.org/content/143/11/3791

Singu, B. S., Srinivasan, P., \& Pabba, S. (2012). Benzoyl peroxide oxidation route to nano form polyaniline salt containing dual dopants for pseudocapacitor. Journal of Electroanalytical Society, 159(1), A6-A13. http://jes.ecsdl.org/content/159/1/A6.short

Tayel, M. B., Soliman, M. M., Ebrahim, S., \& Harb, M. E. (2016). An Introduced Hybrid Graphene/Polyaniline Composites for Improvement of Supercapacitor. Journal of Electronic Materials, 45(1), 820-828. https://link.springer.com/article/10.1007/s11664-015-4212-8

Tezuka, Y., Aoki, K., \& Shinozaki, K. (1989). Kinetics of oxidation of polypyrrole-coated transparent electrodes by in situ linear sweep voltammetry and spectroscopy. Synthetic Metals, 30(3), 369-379.

https://doi.org/10.1016/0379-6779(89)90660-7 
Valentová, H., \& Stejskal, J. (2010). Mechanical properties of polyaniline. Synthetic Metals, 160(7-8), 832-834. https://doi.org/10.1016/j.synthmet.2010.01.007

Vorotyntsev, M. A., Deslouis, C., Musiani, M. M., Tribollet, B., \& Aoki, K. (1999). Transport across an electroactive polymer film in contact with media allowing both ionic and electronic interfacial exchange. Electrochimica Acta, 44(12), 2105-2115. https://doi.org/10.1016/S0013-4686(98)00318-1

Wang, H., Aoki, K. J., Chen, J., Nishiumi, T., Zeng, X., \& Ma, X. (2015). Power law for frequency-dependence of double layer capacitance of graphene flakes. Journal of Electroanalytical Chemistry, 741, 114-119. https://doi.org/10.1016/j.jelechem.2015.01.008

Yu, Y., Zhang, Y., Jiang, Z., Zhang, X., Zhang, H., \& Wang, X. (2009). Full view of single-molecule force spectroscopy of polyaniline in oxidized, reduced, and doped states. Langmuir, 25(17), 10002-10006. http://pubs.acs.org/doi/pdfplus/10.1021/la901169p

Zhao, X., Aoki, K. J., Chen, J., \& Nishiumi, T. (2014). Examination of the Gouy-Chapman theory for double layer capacitance in deionized latex suspensions, RSC Advances, 4(108), 63171-63181. https://doi.org/10.1039/c4ra11258j

Zoltowski, P. (1998). On the electrical capacitance of interfaces exhibiting constant phase element behavior. Journal of Electroanalytical Chemistry, 443(1), 149-154. https://doi.org/10.1016/S0022-0728(97)00490-7

\section{Copyrights}

Copyright for this article is retained by the author(s), with first publication rights granted to the journal.

This is an open-access article distributed under the terms and conditions of the Creative Commons Attribution license (http://creativecommons.org/licenses/by/4.0/). 